\title{
Suplementação nutricional como abordagem terapêutica no transtorno do espectro autista: Uma revisão de literatura
}

\author{
Nutritional supplementation as a therapeutic approach in autistic spectrum disorder: A literature \\ review
}

\section{La suplementación nutricional como enfoque terapéutico en el trastorno del espectro autista: Una revisión de literatura}

\section{Resumo}

Objetivo: Expor a relevância da identificação dos déficits vitamínicos no organismo dos autistas, das inflamações decorrentes desse processo, assim como a influência da suplementação nutricional vitamínica para o desenvolvimento de uma melhor qualidade de vida dessas crianças. Metodologia: Estudo de revisão de literatura, baseado em artigos científicos indexados nas bibliotecas virtuais: MEDLINE, LILACS, SCIELO e Google Acadêmico, realizado entre janeiro e fevereiro de 2021, tendo como critérios de inclusão: artigos completos, nos idiomas: português, inglês e espanhol, publicados nos últimos oito anos e que abordassem a temática na íntegra. Foram excluídos os artigos incompletos, ausentes nas bases de dados referidas e com temas que não supriam a finalidade desta pesquisa. Resultados e discussão: A partir da análise de quinze artigos, verificou-se que a suplementação multivitamínica e mineral consiste em fundamental importância para o autista, haja vista que a seletividade limita a variedade dos alimentos e gera carências nutricionais, fomentando um quadro de desnutrição calórico-proteica. Conclusão: Depreende-se que os indivíduos autistas, com suas dificuldades baseadas nessa tríade, necessitam de suplementos vitamínicos baseados em ômega-3, ferro, vitamina D e vitaminas do complexo B para uma melhor qualidade de vida, haja vista a existência de um déficit de metilação alto que influencia na absorção eficaz dos alimentos, desencadeando inflamações advindas do Sistema Nervoso Central.

Palavras-chave: Transtorno do espectro autista; Suplementos Nutricionais; Vitaminas.

\begin{abstract}
Objective: Expose the relevance of identifying vitamin deficits in the autistic organism, inflammation resulting from this process, as well as the influence of vitamin nutritional supplementation for the development of a better quality of life for these children. Methodology: Literature review study, based on scientific articles indexed in virtual libraries: MEDLINE, LILACS, SCIELO and Google Scholar, conducted between January and February 2021, with the inclusion criteria: full papers in languages: Portuguese, English and Spanish, published in the last eight years and that addressed the issue in its entirety. Incomplete articles absent in databases and those subjects not supplied the purpose of this research were excluded. Results and discussion: From the fifteen articles analysis, it was found that multivitamin and mineral supplementation consisting of fundamental importance for the autism, given that the selectivity limits the variety of foods and generate nutritional deficiencies, stimulating calorie malnutrition above -protein. Conclusion: It
\end{abstract}


appears that autistic individuals, with their difficulties based on this triad, need vitamin supplements based on omega3 , iron, D and B vitamins for a better quality of life, given the existence of a deficit high methylation that influences the effective absorption of food, triggering inflammations from the Central Nervous System.

Keywords: Autistic spectrum disorder; Nutritional supplements; Vitamins.

\section{Resumen}

Objetivo: Exponer la relevancia de identificar los déficits vitamínicos en el organismo de los autistas, de las inflamaciones resultantes de este proceso, así como la influencia de la suplementación nutricional vitamínica para el desarrollo de una mejor calidad de vida de estos niños. Metodología: Estudio de revisión de literatura, basado en artículos científicos indexados en bibliotecas virtuales: MEDLINE, LILACS, SCIELO y Google Académico, realizado entre enero y febrero de 2021, teniendo como criterio de inclusión: artículos completos, en idiomas: portugués, inglés y español, publicados en los últimos ocho años y que abordó el tema en su totalidad. Se excluyeron los artículos incompletos, ausentes en las bases de datos referidas y con temas que no cumplieron con el propósito de esta investigación. Resultados y discusión: A partir del análisis de quince artículos, se verificó que la suplementación multivitamínica y mineral es de fundamental importancia para el autista, dado que la selectividad limita la variedad de alimentos y genera deficiencias nutricionales, propiciando una situación de desnutrición calórica-proteica. Conclusión: Se infiere que las personas autistas, con sus dificultades basadas en esta tríada, necesitan suplementos vitamínicos a base de omega-3, hierro, vitamina D y complejo vitamínico B para una mejor calidad de vida, dada la existencia de un déficit de alta metilación que influye en la absorción efectiva de los alimentos, desencadenando la inflamación derivada del Sistema Nervioso Central.

Palabras clave: Trastorno del espectro autista; Suplementos nutricionales; Vitaminas.

\section{Introdução}

O autismo é um transtorno complexo do desenvolvimento que envolve atrasos e comprometimentos nas áreas de interação social e linguagem, incluindo uma ampla gama de sintomas emocionais, cognitivos, motores e sensoriais (Júnior \& Kuczynski, 2015).

Baseado em uma tríade, o Transtorno do Espectro Autista (TEA) compromete a comunicação, a sociabilização e o comportamento dos indivíduos. O autismo, enquanto condição sistêmica, é derivado de uma causa multifatorial, visto que, os fatores genéticos, quando somados aos fatores ambientais, se configuram como eixos importantes no espectro (Brasil, 2019).

Estima-se que existam 2 milhões de brasileiros autistas, bem como no mundo a perspectiva é de 70 milhões. Estudos moleculares recentes demonstraram que mais de 100 genes possuem uma vasta capacidade de desencadear o autismo, essa quantidade quando aliada a gestação e aos primeiros mil dias de vida da criança, pode acarretar casos mais graves de TEA, visto que, a predisposição de acontecer uma exposição demasiada a poluentes, agrotóxicos, medicamentos, infecções de repetição, casos de encefalites e epilepsia, são abundantes (Brasil, 2019; Arberas \& Ruggieri, 2019).

Outrossim, as crianças autistas possuem desordens gastrointestinais devido a uma disfunção mitocondrial e consequente déficit de metilação, corroborando em inflamações mais frequentes e maiores índices de seletividade alimentar, haja vista alterações no sistema nervoso central e elevadas taxas de stress oxidativo, dificultando a absorção de Ômega-3, Vitamina D, Ferro e Vitaminas do Complexo B (Leite et al., 2020).

A metilação é um processo do metabolismo humano que lida com o DNA e o RNA, ativando ou desativando as expressões gênicas, a depender do tecido envolvido na conjuntura. Nessa perspectiva, a metilação auxilia no desenvolvimento de neurotransmissores, incluindo a dopamina, a qual é envolvida no humor, na cognição, no comportamento, no aprendizado e na atenção dos indivíduos. Além disso, ela ainda produz creatina para fornecer energia ao organismo e contribui na construção de membranas celulares flexíveis que permitem a entrada de substâncias no corpo, como a exemplo de minerais e medicamentos, bem como a remoção de toxinas (Farias, 2018).

Ademais, as reações de metilação são dependentes de enzimas, as quais requerem minerais (zinco e magnésio) e outros nutrientes para facilitar o procedimento, como é o caso das vitaminas, incluindo ácido folínico, B12 na forma metilada (metilcobalamina) e piridoxil-5 fosfato (uma forma ativa de B6) para manter as engrenagens bioquímicas funcionando sem problemas e trabalhando em conjunto. Entrentanto, em crianças neurotípicas, essa nutrição seria disponibilizada mediante o 
consumo adequado de alimentos, porém, nas crianças autistas, é necessário uma suplementação nutricional direcionada, tendo como base uma análise dos biomarcadores (Laake \& Compart, 2013).

Dessa maneira, objetiva-se apresentar a indispensabilidade da identificação dos déficits vitamínicos no organismo dos autistas, das inflamações decorrentes desse processo, assim como a importância da suplementação nutricional vitamínica para o desenvolvimento de uma melhor qualidade de vida dessas crianças.

\section{Metodologia}

O presente estudo trata-se de uma revisão de literatura, com ênfase na suplementação vitamínica nos indivíduos autistas. Segundo Azevedo (2016), a revisão de literatura é encarregada de produzir um panorama bibliográfico extenso acerca do tema selecionado, demonstrando as principais condutas e teorias concentradas sobre determinada temática.

Dessa Maneira, para obtenção dos artigos, realizou-se um levantamento nas bases de dados das bibliotecas virtuais: MEDLINE, LILACS, SCIELO e Google Acadêmico, nos meses de janeiro e fevereiro de 2021, utilizando os seguintes descritores: "transtorno do espectro autista", "suplementos nutricionais" e "vitaminas". Foram encontrados 30 artigos e selecionados 15 após síntese e análise de acordo com os critérios de inclusão e exclusão. Os critérios de inclusão foram: artigos publicados na íntegra entre o período de 2013 a 2020, tendo como idioma: português, inglês e espanhol, que abordasse a temática desejada, e foram excluídos os artigos que não estivessem na sua totalidade, não constasse nas bases de dados citadas, e que o tema não atendesse aos objetivos propostos. Foram aplicadas as variáveis: título, ano de publicação, tipos de sujeitos, objetivo do estudo e a interpretação dos resultados, seguindo com a escolha dos artigos e leitura criteriosa, direcionando a verificação e discussão para a compreensão completa.

\section{Resultados e Discussão}

O autismo, também denominado de Transtorno do Espectro Autista, caracteriza-se por diversas alterações, dentre as quais se destacam a seletividade e recusa alimentar, que, por sua vez, através de uma alimentação e suplementação nutricional propícias podem reduzir significativamente os sintomas. Desse modo, é nítido que o autismo precisa ser trabalhado por uma equipe multidisciplinar aliada a família, para acompanhamento integral da criança (Paula et al., 2014).

A criança autista ao desenvolver-se demonstra uma resistência a mudanças e novidades na alimentação desde os primeiros 6 meses aos 12 meses de vida; no período de 12 a 18 meses mostra-se muito resistente à introdução de novos alimentos na dieta, em 18 a 24 meses poderá apresentar recusa alimentar ou insistir em apenas um tipo de alimento, mantendo a textura, a cor ou a persistência, sobretudo poderá resistir em participar da cena alimentar; dos 24 a 36 meses a criança com TEA terá grande possibilidade de desenvolver uma dificuldade com esse esquema alimentar, em que possuirá maior tendência a permanecer no uso da mamadeira, apresentando rejeição alimentar, não participação das cenas alimentares e falta de adequação aos horários de alimentação. Outrossim, poderá querer comer a qualquer hora e vários tipos de alimentos ao mesmo tempo, também é possível a tolerância de longos períodos sem comer/comer apenas quando a comida for dada na boca ou só comer sozinha (Brasil, 2021).

Nessa perspectiva, é notório que as dificuldades alimentares são muito frequentes em autistas, ocorrendo uma condição comportamental de seletividade alimentar, seguida por uma relutância ou resistência em experimentar novos sabores e novos alimentos, tendo em vista os fatores como cheiro, temperatura e textura. O comportamento relativo a alimentação encontra-se associado a distúrbios centrais do autismo, o que acarreta a ingestão inadequada de nutrientes, devido a limitação da variedade ou repetição (Almeida, 2017).

Os baixos índices de vitaminas e minerais estão sendo associados, atualmente, com deficiências do desenvolvimento, tendo como exemplo as ocasionadas pelo Transtorno do Espectro Autista. Isso acontece porque eles são considerados elementos 
essenciais ao corpo humano, haja vista que são cofatores de reações químicas, são fragmentos de neurotransmissores, de lipídios e de enzimas vitais para o metabolismo corporal (Silva et al., 2014).

O estado nutricional do autista não se encontra atrelado apenas a questão da ingestão alimentar, também depende de processos fisiológicos e metabólicos como a exemplo da digestão e da absorção, que podem induzir a necessidade de inserção de vitaminas e minerais, potencializados em virtude das situações de recusa e seletividade alimentar, frequente em autistas, que podem conduzir a um aporte inapropriado de micronutrientes (Almeida, 2017).

Além disso, estudos apontam uma correlação entre a inserção de suplementação nutricional pré-natal e distúrbios do espectro autista, no qual destaca-se o uso de multivitamínico materno com ou sem a adição de ferro e ácido fólico até o primeiro trimestre, onde esse uso foi associado a menores chances de TEA com deficiência intelectual na criança quando comparado as mães que não ingeriram os multivitamínicos. Assim, a suplementação multivitamínica materna durante a gravidez pode estar inversamente associada ao TEA com deficiência intelectual na criança. Portanto, ocorre a observância de evidências que sustentam a importância da suplementação nutricional durante a gestação, a questão suscita estudos futuros e por si só não devem mudar a prática atual (DeVilbiss et al., 2017).

\subsection{Suplementação Nutricional + Vitaminas e Minerais}

A suplementação nutricional tem como finalidade fornecer nutrientes, substâncias bioativas, enzimas ou probióticos em complemento à alimentação dos indivíduos, sejam eles neurotípicos ou não (Brasil, 2020).

Nas crianças autistas, a suplementação nutricional deve ser iniciada lentamente e orientada por um profissional de saúde, com uma alimentação regrada e de qualidade, visto que, essas crianças possuem uma desordem grastrointestinal potencializada. Dessa maneira, alguns alimentos podem causar estragos nas vilosidades da membrana intestinal ou não realizar com eficiencia a absorção, afetando assim a capacidade de cada suplemento nutricional funcionar de maneira ideal. Portanto, o nutriente deve ser recolhido, digerido e absorvido pelo trato digestivo, transportado para os tecidos, consumido pelas células para, finalmente, ser usado no fornecimento da função (Barbosa \& Figueiró, 2021; Mariano et al., 2019).

No entanto, as taxas de absorção de nutrientes variam para manter a homeostase e evitar a toxicidade no organismo, visto que os níveis de nutrientes corporais são regulados pelas taxas de absorção, metabolização e eliminação. Nessa perspectiva, uma excelente opção para o início da suplementação nutricional é começar pelos que fornecem um maior benefício geral com um menor número de efeitos colaterais, a exemplo do magnésio, do zinco, da vitamina $\mathrm{D}$, dos multivitamínicos, dos ácidos graxos ômega-3 e dos probióticos, todavia sem omitir a indispensabilidade de alguns aminoácidos, das vitaminas A, C e E, das vitaminas do complexo B, do cálcio, do selênio e da coenzima Q10 (Magagnin \& Soratto, 2019).

Assim, quando um autista começa a suplementar os nutrientes precisos, haverão melhorias no seu comportamento, na sua cooperação, no seu sistema sensorial e na sua cognição, corroborando uma maior facilidade de se instalar uma dieta saudável no seu cotidiano (Leite et al., 2019).

\subsection{Estado Nutricional do Autista}

A avaliação do estado nutricional é uma etapa fundamental no estudo de uma criança, uma vez que auxilia na verificação do crescimento infantil e propicia uma melhora na sua qualidade de vida. Além do mais, é um instrumento diagnóstico que abrange as condições nutritivas de cada organismo, as quais são determinadas pelos processos de ingestão, absorção, utilização e excreção, sumarizando um balanço entre a ingesta e a perda de nutrientes (Barros, 2018).

Contudo, a maioria dos indivíduos que apresentam o Transtorno do Espectro Autista apontam níveis elevados de desnutrição e excesso de peso. A dieta dessas crianças são deficitárias no que se condiz a ingesta de fibras, cálcio, ferro, zinco, 
ácido fólico e vitaminas, e intensas no que diz respeito ao consumo de carboidratos, gorduras saturadas e alimentos industrializados, promovendo um acréscimo significativo nos índices dos exames laboratoriais (Brito et al., 2020; Ferreira, 2016).

\section{Conclusão}

A suplementação multivitamínica e mineral no autismo foi objeto de análise do presente estudo, o qual evidenciou a importância de uma suplementação adequada para assegurar uma melhora na qualidade de vida das crianças autistas.

Nessa perspectiva, é notório que a carência alimentar condiciona a uma necessidade de reposição vitamínica ao autista, indo de acordo ao grande déficit. Dessa maneira, ainda há estudos que apontam que o cuidado também deve ser estendido a mãe no período gestacional, devido a imprescindível primordialidade dos nutrientes na saúde do recém-nascido.

No portador do autismo, estudos evidenciam a correlação entre TEA e baixos níveis séricos da vitamina D, considerando-se, contudo, altas latitudes, variações sazonais, ingestão dietética, fatores genéticos, entre outros. Ressalta-se também que o uso de multivitamínicos associados ou não ao ferro e ácido fólico (até o primeiro trimestre de gestação) encontramse ligados a menores chances de TEA com deficiência intelectual, quando comparadas a mães que não fizeram o referido uso.

Assim, é notório que a inserção de uma suplementação adequada na alimentação pode diminuir consideravelmente os sinais e sintomas ocasionados pelo TEA. Ademais, evidencia-se a utilidade do conhecimento acerca do autismo, bem como a imprescindibilidade do acompanhamento multidisciplinar juntamente com a atenção familiar as suas necessidades.

Portanto, espera-se que os trabalhos futuros relacionados à suplementação nutricional nos autistas, retratem, na sua essência, a influência familiar nos hábitos alimentares do indivíduo e a aceitação social dos complementos nutritícios como fortes aliados no tratamento dos portadores do TEA.

\section{Referências}

Almeida, L. A. (2017). A influência da alimentação em crianças autistas. http://docplayer.com.br/88104657-Larissa-aragao-de-almeida-a-influencia-daalimentacao-em-criancas-autistas-lauro-de-freitas.html

Arberas, C., \& Ruggieri, V. (2019). Autismo: Aspectos Genéticos y Biológicos. MEDICINA (Buenos Aires), 79,16 - 21.

Azevedo, D. (2016). Revisão de Literatura, Referencial Teórico, Fundamentação Teórica e Framework Conceitual em Pesquisa - diferenças e propósitos. http://unisinos.academia.edu/DeboraAzevedo/Papers

Barbosa, A. B., \& Figueiró, R. (2021). Autismo: Como amenizar os sintomas através da alimentação e contribuir no processo ensino-aprendizagem. Research, Society and Development, 10(6), e25510615704. https://doi.org/10.33448/rsd-v10i6.15704

Barros, B. S. (2018). Perfil alimentar de crianças com transtorno do espectro autista. https://bdm.unb.br/handle/10483/20721

Brasil, A. N. de. V. S. (2020). Suplementos Alimentares. http://antigo.anvisa.gov.br/suplementos-alimentares

Brasil, M. da. M. da. F. e. dos. D. H. (2019). Ministério celebra o Dia Mundial de Conscientização do Autismo. https://www.gov.br/mdh/ptbr/assuntos/noticias/2019/abril/ministerio-celebra-o-dia-mundial-de-conscientizacao-do-autismo

Brasil, M. S. (2021). Diretrizes de Atenção à Reabilitação da Pessoa com Transtornos do Espectro do Autismo (TEA). https://bvsms.saude.gov.br/bvs/publicacoes/diretrizes_atencao_reabilitacao_pessoa_autismo.pdf

Brasil, S. B. P. (2019). Guia Prático de Atualização: Transtorno do Espectro do Autismo. https://www.sbp.com.br/fileadmin/user_upload/21775c-MO__Transtorno_do_Espectro_do_Autismo.pdf

Brito, A. N. M. de., Santana, C. M. N. de., Torres, M. V., \& Souza, A. S. de. (2020). Estilo de vida associado ao estado nutricional de crianças com autismo. Research, Society and Development, 9(9), e582997663. https://doi.org/10.33448/rsd-v9i9.7663

DeVilbiss, E. A., Magnusson, C., Gardner, R. M., Rai, D., Newschaffer, C. J., Lyall, K., Dalman, C., \& Lee, B. K. (2017). Antenatal nutritional supplementation and autism spectrum disorders in the Stockholm youth cohort: population based cohort study. BMJ, 359.

Farias, M. A. S. (2018). Síndromes Genéticas Associados ao Transtorno do Espectro Autista. https://repositorio.uniceub.br/jspui/handle/235/11706

Ferreira, N. V. R. (2016). Estado nutricional em crianças com transtorno do espectro autista. https://acervodigital.ufpr.br/bitstream/handle/1884/47169/R\%20\%20D\%20-\%20NATERCIA\%20VIEIRA\%20RIBEIRO\%20FERREIRA.pdf?sequence=1\&isAllowed=y

Júnior, F. B. A., \& Kuczynski, E. (2015). Autismo infantil: novas tendências e perspectivas. Atheneu. 
Research, Society and Development, v. 10, n. 9, e1610917745, 2021

(CC BY 4.0) | ISSN 2525-3409 | DOI: http://dx.doi.org/10.33448/rsd-v10i9.17745

Laake, D. G., \& Compart, P. J. (2013). The ADHD and Autism Nutritional Supplement Handbook: The Cutting-Edge Biomedical Approach to Treating the Underlying Deficiencies and Symptoms of ADHD and Autism. Fair Winds Press (MA).

Leite, M. A. C., Silva, S. L., Correia, B. G. B., Santos, M. R., Pereira, C. P., \& Bezerra, A. N. (2019). Intervenção Nutricional no Transtorno Espectro do Autismo. https://doity.com.br/media/doity/submissoes/5da4af79-0a64-4f0f-a79c-5fec43cda1d7-resumo-autismo-corrigidopdf.pdf

Leite, M. C., Morais, S. A. de., Ribeiro, C. C. F., Souza, V. V. S., Oliveira, C. S., \& Duarte, M. S. A. (2020). Análise dos efeitos gastrointestinais no Transtorno do Espectro Autista (TEA). Amplamente: saúde e bem-estar, 1(1), 26 - 38.

Magagnin, T., \& Soratto, J. (2019). Autismo: comer para nutrir.

Mariano, A. C. de. O., Alves, A. M. P., Perles, J. V. C. M., \& Defani, M. A. (2019). Autismo e as Desordens Gastrintestinais. Arquivos do MUDI, $23(3), 387$ 398.

Paula, F. M. de., Silvério, G. B., Jorge R. P. C., Felício, P. V. P., Melo, L. A. de., Braga T., \& Carvalho, K. C. N. (2020). Transtorno do Espectro do Autismo: Impacto no Comportamento Alimentar. Brazilian Journal of Health Review, 3(3), 5009-5023.

Silva. V. B., Mundim, A. F. R., Almeida, M. T. C., Silveira, M. F., Saeger, V. A., Parrela, C. P., \& Maia, F. A. (2014) Tratamento Nutricional Infantil do Transtorno do Espectro do Autismo - Uma Revisão de Le Riteratura. http://www.fepeg2014.unimontes.br/sites/default/files/resumos/arquivo_pdf_anais/tratamento_nutricional_infantil_do_transtorno_do_espectro_do_autismo__uma_revisao_de_literatura.pdf 